\title{
O TELETANDEM COMO ESPAÇO PARA APRENDIZAGEM E FORMAÇÃO DE PROFESSORES DE LÍNGUAS
}

\author{
Rickison Cristiano de Araújo Silva \\ Fábio Marques de Soura ${ }^{* *}$
}

RESUMO: O cenário educacional no qual estamos inseridos, é caracterizado pelas constantes transformações e surgimento de recursos tecnológicos que perpassam o contexto social e digital, proporcionando novas formas ao ensinar, aprender e formar professores de línguas. Neste sentido, o Teletandem, um contexto de aprendizagem virtual, assistida pelo computador por meio de interações através de imagens em vídeo, autônomo, colaborativo e intercultural, apresenta-se como uma oportunidade única de trocas linguísticas e culturais, desenvolvendo uma formação intercultural no estudante e no futuro professor de línguas. Este artigo objetiva discutir a respeito do Teletandem como um contexto que proporciona a aprendizagem de línguas, e em especial, a formação de professores de línguas. Para tanto, utilizamos como referencial teórico Telles (2009), Benedetti (2010), Serrani (2005) entre outros.

PALAVRAS-CHAVE: Teletandem; Formação de professores; Interculturalista; Aprendizagem de línguas.

\footnotetext{
* Mestrando no Programa de Pós-Graduação em Linguagem e Ensino da Universidade Federal de Campina Grande (PPGLE/UFCG). Integrante do Grupo de pesquisa TECLIN: Tecnologias, Culturas e Linguagens cadastrado no DGP do CNPq.

** Doutor em Educação pela Universidade de São Paulo (Usp). Professor da Universidade Estadual da Paraíba (UEPB).
} 


\section{Considerações iniciais}

O ensino de línguas, na contemporaneidade, está marcado pelas diversas transformações que permeiam a esfera social e digital, que influenciam diretamente no comportamento da sociedade, na formação de professores e na forma como se ensina e aprende uma língua. Assim, os professores de línguas, perpassados por um contexto globalizado, interdisciplinar e intercultural, são motivados a questionar constantemente sua formação e práticas docentes que inserem a cultura e o uso das Tecnologias Digitais da Informação e Comunicação, doravante TDICs, como eixos importantíssimos da formação e, da atuação dos profissionais de línguas.

Neste sentido, visualizamos que algumas universidades e os cursos de formação de professores de línguas apresentam somente, na maioria das vezes, uma preocupação para o desenvolvimento de uma competência linguística nos alunos, ao invés de inserir estudos e reflexões a respeito das tecnologias e interculturalidade durante a formação dos professores, seja em componentes curriculares que versem sobre a cultura digital e aspectos aliados à formação docente, como também ao uso da internet e das tecnologias digitais no ensino de línguas, resultando na falta de uma reflexão sobre as inúmeras possibilidades existentes na prática docente (CELANI, 2010).

Destarte, entendemos que a formação de professores solicita novas demandas, dentre elas, percebemos a urgência em formar profissionais que além de críticos e reflexivos, consigam transitar em uma perspectiva intercultural mediada pelas TDICs, chamados aqui como "interculturalista", o professor de línguas que caminha pelas mais diversas culturas no ato de reconhecer-se no diferente, no outro, aquilo que aparentemente é longe de sua realidade (SERRANI, 2005).

Posto isto, o Teletandem no cenário de formação de professores de línguas se apresenta como um contexto inovador, colaborativo, autônomo, digital e relevante, visto que temáticas como estas promovem discussões muitas vezes esquecidas, como a de oportunidades para trocas linguísticas, profissionais, sociais e principalmente interculturais. 
Neste estudo, temos como objetivo discorrer sobre o Teletandem como o espaço para aprendizagem de línguas, e em especial na formação de professores de línguas. Assim, se faz necessário apresentarmos primeiramente suas principais características e os princípios que o norteiam. Em seguida, realizamos um panorama de pesquisas referentes a dissertações e teses, presentes no banco de dados da Capes, na área de formação de professores no Teletandem, um contexto autônomo, colaborativo e digital, sob o viés da interculturalidade, temática esta que se configura de forma inovadora em relação ao cenário convencional no qual estamos acostumados a tratar. Concomitante, caracterizamos nossa pesquisa ${ }^{1}$ de dissertação em desenvolvimento através do Programa de Pós-graduação em Linguagem e Ensino (PPGLE), acerca da formação do professor de língua espanhola interculturalista a partir do Teletandem. Por fim, apresentamos as considerações finais.

\section{Ensino e aprendizagem de línguas em tandem}

A palavra Tandem é de origem latina e se refere a uma bicicleta operada por duas pessoas, diferenciando-se da bicicleta convencional. A bicicleta é composta por dois assentos, no qual os dois usuários pedalam ao mesmo tempo, ou seja, percorrem todo o trajeto de forma colaborativa. Dessa forma, a aprendizagem em Tandem, iniciada de forma presencial, é caracterizada como um contexto autônomo, colaborativo e recíproco de aprendizagem de Língua Estrangeira - LE, fundamentado em princípios e acordos para as realizações das interações bilíngues, que acontecem entre dois parceiros, competentes ou nativos na língua, cujo objetivo está centrado na aprendizagem da LE.

De origem alemã, a aprendizagem de línguas estrangeiras em Tandem foi idealizada no final da década de sessenta, do século XXI, utilizada pela primeira vez na parte final de cursos bilíngues, cujo método era o audiovisual, tratando-se de pequenas atividades, escritas e conversas, previamente realizadas entre dois falantes de línguas estrangeiras, deixando

\footnotetext{
${ }^{1}$ Título: "A formação do professor interculturalista de Língua Espanhola mediada pelo Teletandem: Crenças, ações e reflexões", sendo orientado pelo professor Dr. Fábio Marques de Souza, A pesquisa foi aprovada pelo comitê de ética em 19 de fevereiro de 2018. CAAE: 06702818.3.0000.5182.
} 
de lado a autonomia dos alunos. Nos anos setenta, o primeiro país no qual a prática de Tandem se difundiu foi a Espanha, adotando a perspectiva que se utiliza atualmente, ou seja, um contexto de aprendizagem de LE entre falantes nativos de diferentes línguas, cujo objetivo está em ensinar e aprender de forma colaborativa e autônoma.

Nos anos seguintes, a aprendizagem em Tandem ganhou mais notoriedade, e por volta dos anos 80, as universidades começaram a estudar e investigar algumas das suas principais características, como a da autonomia, e nos anos 90, teve seus princípios criados e sistematizamos, no qual perduram até os dias atuais, de forma que originou a Rede Internacional de Tandem, subsidiando as futuras pesquisas no período (TELLES, 2009).

Dentre os princípios presentes nas interações em Tandem, Telles e Vassallo (2009) nos apresentam três, que são: Separação das línguas, Reciprocidade e Autonomia. No primeiro princípio, as línguas estrangeiras durante as interações não devem ser misturadas, ou seja, existe um tempo específico para cada língua, com intuito de fazer com que os aprendizes tentem falar na língua e se sintam motivados para tal, promovendo compromisso e envolvimento nas interações. No princípio da reciprocidade, os interagentes são livres de compromisso financeiro, não é cobrado nenhuma quantia para a realização das interações, uma "troca mútua de conhecimento acerca da língua e da cultura alvos" (TELLES; VASSALLO, 2009, p. 24). Livres para escolher o que estudar, a duração, quando, onde e o quê estudar, os interagentes do Tandem possuem liberdade para decidir os pontos elencados acima, viés este que o caracteriza como autônomo, seu terceiro princípio.

Neste sentido, a autonomia se torna um grande aliado no desenvolvimento dos aprendizes durante as interações, pois eles são responsáveis pelo seu próprio processo de aprendizagem, uma vez que algumas questões relativas ao que (não) fazer durante as sessões são de responsabilidade deles na maioria das vezes. Assim, o Tandem se apresenta como flexível e aberto referente a realização dos encontros, podendo se encontrar diariamente, semanalmente, três vezes na semana, ou outro período que for melhor para os pares. 
Telles e Vassallo (2009) pontuam que o contexto de aprendizagem em Tandem é de extrema importância para os professores, pesquisadores e professores formadores de línguas estrangeiras, pois visibiliza inserir o aluno em contato com um falante nativo ou proficiente da língua no qual ele está aprendendo, um excelente espaço para pesquisas no campo da Linguística Aplicada fornecendo um ambiente complexo de aprendizagem colaborativa e comunicativa.

Com base em Cziko (2004 apud TELLES; VASALLO, 2009, p. 27), o Tandem apresenta "um contexto peculiar, porque compartilha aspectos tanto de contextos naturais, como da instrução formal, tendo a singularidade de combinar os melhores aspectos de ambos". Ou seja, trata-se de um contexto que apresenta características próprias que emergem e/ou oscilam dos seus princípios, bem como desafia a "posição do professor durante o processo de aprendizagem - uma posição que requer atitudes alternativas da parte do professor com relação ao aconselhamento".

Dentro do contexto de aprendizagem tratado ao longo das nossas discussões, há uma preocupação em deixar explícito para os alunos e demais interessados na área as principais características do Tandem para que não ocorra uma má interpretação do que de fato consiste esse contexto específico de aprendizagem colaborativa e autônoma de línguas estrangeiras. Neste sentido, pontuaremos a seguir algumas das não características que o Tandem é ou tenta promover.

O primeiro aspecto que pontuamos é que o Tandem não promove sessões de batepapos, como alguns podem imaginar. Para que sejam realizadas as interações, os participantes seguem alguns princípios, regras e objetivos. Um deles está no encontro sistemático entre os parceiros, marcado por uma quantidade de hora exata, ao invés de um encontro "inesperado" ao longo do dia. Durante as conversações os interagentes necessitam estar atentos a dois movimentos: o que o outro está dizendo e como ele está dizendo, ou seja, o movimento do conteúdo/significado e o da forma. Não obstante, temos um dos principais pontos presentes nas interações que é o desenvolvimento da competência linguística e a 
cultural, e não somente a proficiência na língua-alvo, mas a concretização dessas competências.

Outro aspecto que os estudiosos pontuam é que existe uma diferença entre estudar LE em Tandem e estudá-la de forma individual, mesmo que para alguns não exista tal perspectiva, não sendo deste modo um estudo autodirigido. Pontuamos que o Tandem é um contexto de aprendizagem colaborativa e que gera uma força nas crenças que trazemos muitas vezes na hora de aprender uma nova Língua. E por fim, as interações realizadas através do Tandem não a caracteriza como uma aula particular por ser colaborativo, não há acordos financeiros e porque as sessões acontecem de forma livre e gratuita na intenção de compartilhar com o outro seus conhecimentos sobre sua língua nativa ou proficiente.

Neste sentido, vemos que o Tandem se caracteriza como um contexto colaborativo de aprendizagem, no qual há um esforço duplo dos falantes interagentes, bem como a promoção da autonomia dos alunos no processo de aprendizagem, no qual não há necessariamente o foco na aprendizagem, mas sim uma experiência na língua estrangeira (VASSALO; TELLES, 2009).

\section{Do tandem ao teletandem}

A aprendizagem em tandem começou sua prática sem o uso das tecnologias digitais, sendo realizada de forma presencial e só depois, com o surgimento e incorporação das tecnologias no dia a dia dos usuários e no ensino de línguas, vários recursos tecnológicos começaram a proporcionar outros tipos de modalidades de tandem, proporcionando interações síncronas e assíncronas.

Desta forma, o tandem começou a ser realizado das seguintes formas: (1) Presencial, sendo chamado também de "face a face". Os pares se encontram em um lugar específico para aprender cada um a língua do outro, podendo ser uma sala de aula, restaurante, casa dos participantes, dentre outros lugares; (2) E-tandem, envolve a comunicação assíncrona como a carta e o e-mail, e síncrona o telefone, chats e mensagens de voz, possibilitando a interação dos pares que não estão no mesmo ambiente, ou seja, não compartilham dos 
mesmos espaços físicos e geográficos; e (3) Teletandem, que vai além das duas formas apresentadas. Aqui, esta forma possibilita uma experiência de interação completa, com a presença de multirecursos, ou seja, a presença da escrita e do audiovisual (VASSALLO, 2006).

As práticas de Teletandem, termo proposto por Telles a partir do projeto "Teletandem Brasil: Línguas estrangeiras para todos ${ }^{2}$ ”, propõem o processo de ensino e aprendizagem realizado através do computador conectado à internet, a distância, a partir de uma comunicação sincrônica, utilizando recursos que possibilitam a escrita, leitura, e videoconferências, a partir de novos ambientes de aprendizagem, aplicativos e programas de mensagens instantâneas, tais como o Skype, Windows Live Messenger e o OoVoo .

Benedetti (2010) pontua que esta forma de tandem se aproxima bastante ao modelo face a face, pelo fato de que os interagentes podem se comunicar oralmente através do plano visual pela webcam com um microfone. Nesta perspectiva, acredita-se que a prática de Teletandem possibilita também a percepção das feições e expressões faciais, os gestos, e mudanças de entonação na voz do seu interagente, tornando aquele momento mais autêntico, facilitando a negociação e a compreensão dos significados de forma sincrônica, ou seja, em tempo real.

Para que sejam realizadas as interações no Teletandem, além de levarmos em consideração os princípios próprios presentes na modalidade tandem, se faz necessário compreender pelo menos três dos princípios teóricos do Teletandem, a saber:

(1) Igualdade e Separação de línguas: Aqui os pares necessitam alternar as línguas durante a interação. Ou seja, cada língua terá seu momento durante as sessões de

\footnotetext{
${ }^{2}$ Projeto de pesquisa que faz parte do Programa de Pós-Graduação em Estudos Linguísticos da Universidade Estadual Paulista São José do Rio Preto, na área da Linguística Aplicada (Aprendizagem de línguas assistida pelo computador, de didática e da educação de professores).
}

Site: http://www.teletandembrasil.org/ 
forma igualitária, cada língua alternada terá o mesmo tempo, fazendo com que não haja uma confusão de línguas;

(2) Reciprocidade: Os participantes alternam os papeis durante as interações, ora de aprendiz da língua alvo, ora instrutor da sua língua materna. Esta característica faz com que haja um compromisso para com o seu parceiro, na certeza de que haverá um engajamento mútuo para que se atinja os objetivos propostos pelos dois, realizando um trabalho em conjunto;

(3) Autonomia: Neste princípio, cada um dos participantes é responsável pelas suas próprias decisões em relação a sua aprendizagem, gerenciando suas metas e necessidades de acordo com o objetivo que ele almeja.

Pontuamos, a partir das contribuições de Benedetti (2010), que dentro da aprendizagem em Tandem os interagentes não irão somente decidir o que farão ao longo do seu processo de aprendizagem diante daquilo que eles desejam aprender e de como alcançarão tal feito, bem como a quantidade de tempo que este levará com o auxilio de seu parceiro, mas igualmente estar compromissado em ajudar no processo do outro para que ele também consiga alcançar suas metas e objetivos na língua-alvo. Assim, a autonomia é vista como um vínculo norteado por acordos e comum.

Deste modo, as práticas de Teletandem são inseridas no campo de ensino/aprendizagem de línguas como uma atividade complementar da sala de aula, uma vez que os estudantes estarão em contato com falantes nativos da língua meta, através de uma interação, ou seja, escrita e audiovisual, em tempo real entre os participantes, possibilitando-lhes um intercâmbio de conhecimentos de diferentes culturas, que além de aprender a língua de forma colaborativa, em ambientes comunicativos, converte-se em um contexto de reflexões acerca da sua formação para os futuros professores de línguas estrangeiras numa perspectiva intercultural. 
No Teletandem os participantes estão interessados em estudar a língua do outro, podem ou não ser falante nativo da língua-alvo do parceiro, e nem necessariamente professores de línguas formados. A realização das sessões se dá de forma regular, com um fim pedagógico, didático, no qual cujas interações são posteriormente regadas de uma reflexão compartilhada sobre a fala, cultura, comunicação dentre outros, revisando os diários de bordo realizados durante as sessões.

A aprendizagem no Teletandem parte de um viés sociocultural do desenvolvimento humano, pois concebe a aprendizagem como um processo socialmente mediado, uma vez que estamos falando de duas pessoas, cuja língua materna não é a mesma, e que acabam se ajudando de forma colaborativa a fim de alcançar objetivos como conhecimentos linguísticos, culturais, ou até mesmo outras informações preestabelecidas por eles.

\section{Formação de professores de línguas no Teletandem}

No âmbito brasileiro de pesquisas sobre a formação de professores de línguas, evidenciamos a considerável produção de teses, dissertações e estudos interessados em investigar esta temática, no entanto são poucos ainda aqueles que voltam seus interesses para reflexões e discussões sobre a formação inicial de professores de línguas sob a perspectiva intercultural num contexto inovador, colaborativo, autônomo e virtual como o Teletandem.

Assim, através do banco de dados de dissertações e teses da CAPES, encontramos a partir do termo "Teletandem" 24 dissertações e 21 teses ${ }^{3}$ produzidas durante os anos de 2008 a 2018 e, em relação a temas referente à cultura e a interculturalidade no ensino e aprendizagem e formação inicial de professores de línguas, somente 2 dissertações e 3 teses foram desenvolvidas. A seguir, visualizamos estas pesquisas no Quadro 1, seguidas de um breve comentário analítico.

\footnotetext{
${ }^{3}$ Nossa pesquisa realizou-se em fevereiro de 2019.
} 
Quadro 1: Pesquisas sobre Teletandem do banco de dados da Capes.

\begin{tabular}{|c|c|c|c|c|}
\hline \multicolumn{5}{|c|}{ Dissertações - Mestrado } \\
\hline $\mathbf{N}^{\mathbf{o}}$ & Região & Título & Autor - Data & Instituição \\
\hline 1 & Sudeste & $\begin{array}{l}\text { Crenças sobre a língua inglesa: o anti- } \\
\text { americanismo e sua relação com o } \\
\text { processo de ensino - aprendizagem de } \\
\text { professores em formação. }\end{array}$ & $\begin{array}{c}\text { MENDES } \\
(2009)\end{array}$ & $\begin{array}{l}\text { UNESP, São } \\
\text { José do Rio } \\
\text { Preto. }\end{array}$ \\
\hline 2 & Sudeste & $\begin{array}{l}\text { A articulação língua-cultura na co- } \\
\text { construção da competência intercultu- } \\
\text { ral em uma parceria de teletandem } \\
\text { (português / espanhol). }\end{array}$ & $\begin{array}{c}\text { RODRI- } \\
\text { GUES (2013) }\end{array}$ & $\begin{array}{l}\text { UNESP, São } \\
\text { José do Rio } \\
\text { Preto. }\end{array}$ \\
\hline \multicolumn{5}{|c|}{ Teses - Doutorado } \\
\hline $\mathbf{N}^{\mathbf{o}}$ & Região & Título & Autor - Data & Instituição \\
\hline 1 & Sudeste & $\begin{array}{l}\text { A cultura e o ensino de língua estran- } \\
\text { geira: perspectivas para a formação } \\
\text { continuada no projeto Teletandem } \\
\text { Brasil. }\end{array}$ & $\begin{array}{l}\text { SALOMÃO } \\
(2012)\end{array}$ & $\begin{array}{l}\text { UNESP, São } \\
\text { José do Rio } \\
\text { Preto. }\end{array}$ \\
\hline 2 & Sudeste & $\begin{array}{l}\text { Cultura e }(\mathrm{m}) \text { telecolaboração: uma } \\
\text { análise de parcerias de teletandem } \\
\text { institucional. }\end{array}$ & ZAKIR (2015) & $\begin{array}{l}\text { UNESP, São } \\
\text { José do Rio } \\
\text { Preto. }\end{array}$ \\
\hline 3 & Sudeste & $\begin{array}{l}\text { Teletandem e mal-entendidos na co- } \\
\text { municação intercultural on-line em } \\
\text { língua estrangeira. }\end{array}$ & $\begin{array}{c}\text { SOUZA } \\
(2016)\end{array}$ & $\begin{array}{l}\text { UNESP, São } \\
\text { José do Rio } \\
\text { Preto. }\end{array}$ \\
\hline
\end{tabular}

Fonte: Elaborado pelo pesquisador, 2019.

Em relação ás pesquisa no âmbito de dissertação, temos a de Mendes (2009) intitulada "Crenças sobre a língua inglesa: o antiamericanismo e sua relação com o processo de ensino-aprendizagem de professores em formação", que investiga pontos relacionados a temática da interculturalidade, tais como estereótipos, preconceito, cultura, alteridade, iden- 
tidade e outros presentes durante as interações de Teletandem, realizadas por uma estadunidense e uma brasileira, professora em formação inicial. Durante a pesquisa, percebeu-se a confirmação de crenças por parte da brasileira a respeito dos Estados Unidos e de sua relação com a língua inglesa, bem como estereótipos sobre os estadunidenses, ou seja, a cultura. O pesquisador pontua também que o teletandem se apresenta como um contexto favorável para a promoção da interculturalidade, bem como a confirmação e ressignificação de crenças que os alunos de LE apresentam.

Rodrigues (2013) em “A articulação língua-cultura na coconstrução da competência intercultural em uma parceria de Teletandem (português/espanhol)" apresenta uma pesquisa qualitativa de base etnográfica, no qual teve como principal objetivo investigar de que forma os aspectos linguísticos e culturais foram articulados por um participante brasileiro, estudante de Letras com habilitação em português e espanhol e outra uruguaia, formada em Licenciatura em Português, durante as sessões de Teletandem. O estudo em questão evidenciou que as sessões de Teletandem na aprendizagem de línguas atuam como um potencializador na coconstrução da competência intercultural dos interagentes por meio das negociações de significados linguístico-cultural e do confronto de valores socioculturais durante as interações.

Percebemos nas duas dissertações apresentadas, Rodrigues (2013) e Mendes (2009), a presença do Teletandem como um contexto que proporciona o desenvolvimento da competência intercultural no processo de ensino e aprendizagem de línguas, descontruindo possíveis estereótipos existentes, bem como a ressignificação de crenças que os alunos apresentam durante o processo, uma vez que o ensino e a aprendizagem de línguas podem passar

[...] uma visão de cultura muito limitada, em que apenas os elementos mais visíveis são levados em conta, como a alimentação, os lazeres, as atividades cotidianas, tratando tudo de forma homogênea e estereotipada: todos os habitantes de um dado país, todos os falantes de uma dada língua agem, pensam e falam de uma mesma forma. (CORACINI, 2007, p. 157) 
Neste sentido, pontuamos que estas duas pesquisas apresentam objetivos e perspectivas distintas em relação a presença da interculturalidade e sua relação com os interagentes para com a nossa pesquisa de mestrado em desenvolvimento. Rodrigues (2013) apesar de ter como participante graduando em língua espanhola, sua pesquisa não está voltada para a formação desse futuro professor enquanto interculturalista de forma específica, mas sim na coconstrução da competência intercultural enquanto aprendiz e falante da língua espanhola. Já na de Mendes (2009), os participantes e a língua estrangeira presente durante as sessões de Teletandem fazem referência à língua inglesa, e não espanhola, diferenciando um pouco do nosso viés. A pesquisa em questão estava interessada em estudar as crenças de participantes professores em formação de língua inglesa sobre a língua estudada por eles, bem como aos Estados Unidos.

Verifica-se então que apesar da pesquisa de Mendes (2009) apresentar um olhar sobre as crenças dos professores em formação inicial, da mesma forma que apresentamos, constatamos que o viés dado para essas crenças diverge, pois o estudioso analisou as crenças em relação a língua estudada e a um determinado país, os Estados Unidos, enquanto em nossa pesquisa objetivamos perceber que crenças os licenciandos em Letras - Espanhol apresentam durante a formação inicial de professores interculturalista, trazendo a tona questões fundamentais sobre o processo de formação docente levando em consideração a interculturalidade, e não somente a aprendizagem de línguas.

Em relação as Teses, destacamos as investigações de Salomão (2012), Zakir (2015) e Souza (2016) que versam sobre a formação de professores de línguas, bem como a presença da interculturalidade nas sessões de Teletandem e discussões sobre as Tecnologias Digitais na formação e prática docente, pontos elencados em nossa dissertação.

Salomão (2012), ao pesquisar " A cultura e o ensino de língua estrangeira: perspectivas para a formação continuada no projeto Teletandem Brasil', teve como objetivo compreender as concepções que professores apresentavam sobre cultura e suas crenças a respeito das noções de língua-cultura que ensinam, bem como o desenvolvimento de reflexões para o contexto de formação continuada que aborde tais aspectos de forma teórica e prática. Para isso, a 
pesquisadora realizou um curso de extensão destinado a professores de espanhol da rede pública de ensino, no interior do estado de São Paulo, oferecido pelo projeto “Teletandem Brasil: línguas estrangeiras para todos".

Visualizamos que Salomão (2012) realizou um curso de extensão, cuja abordagem apresentada ratificava a presença de cultura na formação continuada de professores de espanhol, diferentemente da nossa proposta, cujo contexto se dará em uma disciplina do curso de Licenciatura em Letras - Espanhol ${ }^{4}$, no qual os participantes são professores em formação inicial. Pontuamos também que todos os encontros interativos entre os participantes, pesquisador e sessões de Teletandem serão consideradas como dados primários da pesquisa, diferentemente do que a estudiosa fez, preferindo somente as atividades realizadas. Elencamos também, que apesar de apresentarmos contextos diferentes, a pesquisa da estudiosa promoveu discussões e reconceitualizações de termos que perpassam os dois trabalhos, tais como cultura, interculturalidade, competência comunicativa, e da indissociabilidade entre língua e cultura na formação docente e no processo de ensino e aprendizagem de línguas.

Em "Cultura e (m) telecolaboração: uma análise de parcerias de teletandem institucional", Zakir (2015) investigou as concepções de cultura no contexto de parcerias telecolaborativas entre discentes de uma universidade pública no Brasil e uma privada nos Estados Unidos. A pesquisa fazia parte do projeto "Teletandem e transculturalidade na interação on-line em línguas estrangeiras por webcam", dentro do eixo temático "modos de compreender a cultura do parceiro e seus impactos sobre a aprendizagem e sobre a relação". Teve como corpus analítico as atividades realizadas pelos participantes da pesquisa em uma plataforma virtual de aprendizagem - AVA e as gravações das interações de Teletandem a fim de identificar as noções de cultura. A pesquisadora aponta que sua investigação proporciona reflexões acerca da formação de professores e até mesmo de outros profissionais que estão inseridos

${ }^{4}$ Componente Curricular: Práticas de Intercâmbio Linguístico-Cultural via Teletandem (60h). 
em um contexto que não apresenta barreiras geográficas, promovendo um perfil transcultural através do contato com as mais diversas línguas e consequentemente culturas.

Na pesquisa de Zakir (2015), percebemos que os aspectos culturais se apresentam como norte de toda a pesquisa, e que suas discussões estão voltadas para a formação de professores de línguas no viés transcultural, divergindo do nosso olhar, que apesar de estarmos também preocupados com a formação docente, nossa perspectiva está voltada para o aspecto intercultural, na compreensão do outro e da sua própria cultura durante as interações.

Souza (2016) investigou na pesquisa "Teletandem e mal-entendidos na comunicação intercultural online em língua estrangeira" o processo de negociação de sentidos presentes, predominantemente nas questões linguísticas, discursivas e sociais, bem como a emergência de mal-entendidos nas sessões de Teletandem, cujos interagentes eram aprendizes do par português-inglês, entre uma universidade brasileira e uma universidade norteamericana. Esta pesquisa foi desenvolvida dentro do projeto guarda-chuva Teletandem: Transculturalidade na interação on-line em línguas estrangeiras por webcam.

Percebemos que esta pesquisa, ao tratar sobre os mal-entendidos acontecidos durante as sessões de Teletandem, também aborda fatores culturais e outros adjacentes, cujo interesse perpassa a efetivação da comunicação intercultural. Estes aspectos se apresentam como relevante no processo de ensino e aprendizagem e formação docente.

Nós professores e alunos, não estamos preparados para compreender que ensinar uma língua estrangeira é oferecer experiências de estranheza, capazes de nos reconhecer e, por vezes, de reconhecer o outro (e, portanto, de compreendê-los); situações que provocam confrontos internos, contradições e conflitos que resultam do trabalho do inconsciente, trazendo deslocamentos pela aceitação do outro, da diferença, da não-coincidência de si consigo mesmo, de si com os outros, do que se diz e do que se tem a intenção de dizer. (CORACINI, 2007, p. 158) 
Pontuamos que as sessões de Teletandem promovem essa possibilidade de estranhamento para com o outro, mas que ao mesmo tempo, promove atitudes interculturais a partir do diferente, desse outro que está do outro lado da tela.

Percebemos desta forma, que tais pesquisas centravam seus olhares na formação inicial e continuada de professores sobre a perspectiva intercultural, a presença da cultura e interculturalidade no ensino de línguas mediada nas interações de Teletandem.

Assim, nosso estudo de mestrado antes mencionado parte da ideia de que: (i) a sala de aula de línguas é um ambiente que proporciona momentos de intercâmbio cultural entre os envolvidos, professor e alunos, (ii) as práticas de Taletandem se convertem em uma atividade complementar ao processo de aprendizagem de línguas, da que acontece na sala de aula, e que estamos acostumados e (iii) que o processo de ensino/aprendizagem de uma língua, bem como a formação docente não se fundamenta somente aos aspectos gramaticais de forma descontextualizada, acreditamos na formação do professor interculturalista a partir do Teletandem, que pode ser entendido como o profissional "de língua materna ou estrangeira - apto para realizar práticas de mediação sociocultural, contemplando o tratamento de conflitos identitários e contradições sociais, na linguagem da sala de aula”, posto que ensinar e formar profissional de línguas é um processo intercultural e de reconhecimento da cultura do “outro” (SERRANI, 2005, p. 15).

Desenvolver uma identidade interculturalista é contribuir para que o professor em formação inicial transforme a sua perspectiva, seu horizonte de compreender a realidade, assumindo novos pontos de vista ou até mesmo diferentes interpretações da realidade ou de relação social estabelecida. É além do mais, acreditar numa formação que está desenvolvida em contextos multiculturais, preparando professores para atender de forma coerente à diversidade cultural, ao reconhecimento do outro. E para que seja promovida de fato essa formação intercultural, Matos (2014, p. 5) acredita que todo o processo formativo, desde o planejamento até as diretrizes devam ser culturalmente sensíveis aos indivíduos em interação e "que dentro dessa perspectiva intercultural, a língua passa a ser a ponte, a dimensão 
mediadora entre sujeitos/mundos culturais, visto que o seu enfoque se dará nas relações de diálogo, no lugar da interação".

É neste sentido que as práticas de Teletandem apresentam-se como uma oportunidade sine qua non para a formação de professores interculturalistas, uma vez que o aluno é convidado a vivenciar momentos colaborativos e interculturais.

\section{Considerações finais}

De acordo com as buscas realizadas, percebe-se que as produções referentes à temática de Teletandem, cultura e interculturalidade no processo de formação inicial de professores de línguas, disponíveis no banco de dados da Capes, se centram majoritariamente na região do Sudeste, no Programa de Pós-graduação em Estudos Linguísticos da UNESP, na cidade de São José do Rio Preto, demonstrando um alto índice de produtividade e interesse pela temática.

No entanto, o Nordeste apresenta somente duas pesquisas já desenvolvidas que dialogam com o Teletandem, que são a de Souza (2016) referente ao Pós-Doutorado desenvolvida no Programa de Pós-graduação em Educação Contemporânea (PPGEduc) da Universidade Federal de Pernambuco, cujo olhar está voltado para a mediação do complexo processo de ensino/aprendizagem de línguas estrangeiras/adicionais com o apoio das TDICs, e a dissertação de mestrado de Silva (2018) no Programa de Pós-graduação em Formação de professores (PPGFP), voltada para a multimodalidade na aprendizagem de língua espanhola, no contexto de educação básica.

Levando em consideração as pesquisas já realizadas, e particularmente a de mestrado em desenvolvimento, abordada também neste estudo, consideramos o Teletandem como contexto enriquecedor para o desenvolvimento da interculturalidade no ensino e aprendizagem de línguas e principalmente na formação de professores interculturalistas, visto que nos permite formar professores mais conscientes, que trazem para as sessões informações culturais que seu par não sabia, construindo a partir do diálogo a compreensão do outro e da sua própria cultura a partir da língua. 
Desta forma, o desenvolvimento desse viés intercultural na formação dos professores de línguas e na aprendizagem significa ir além de conhecer e aprender e ensinar uma determinada cultura. Assim, as práticas de Teletandem na formação inicial dos professores de línguas promovem contatos com outros indivíduos de culturas diferentes, desenvolvendo desta forma atitudes e formação interculturais.

Desta forma, acreditamos que ao promover as sessões de Teletandem para os professores em formação desenvolveremos o viés interculturalista, que se apresenta como um importante fator com o apoio tecnológico, no qual sempre fez parte da aprendizagem de língua, porém atualmente, adquiriu uma crescente importância, uma vez que língua e cultura formam um único bloco, fazendo-se necessário perpassar na formação de professores de língua num viés interculturalista, que de acordo com Serrani (2005, p. 17) "requer capacitação para que ele não conceba seu objeto de ensino - a língua - como um mero instrumento a ser 'dominado' pelo aluno”.

\section{EL TELETANDEM COMO ESPACIO PARA APRENDIZAJE Y FORMACIÓN DE PROFESORES DE LENGUAS}

RESUMEN: El escenario educacional en lo cual estamos inseridos, es caracterizado por las diversas transformaciones y surgimientos de recursos tecnológicos que permean el contexto social y digital, desarrollando nuevas formas al enseñar, aprender y formar profesores de lenguas. Así, el Teletandem, un contexto de aprendizaje virtual, asistida por el ordenador a partir de interacciones a través de imagen en vídeo, autónomo, colaborativo e intercultural, se presenta como una oportunidad única de intercambios lingüísticos y culturales, desarrollando una formación intercultural en el estudiante y en el futuro profesor de lenguas. Este artículo tiene como objetivo discutir a respecto del Teletandem como un contexto que proporciona aprendizaje de lenguas, y en especial, la formación de profesores de lenguas. Para tanto, utilizamos como referencial teórico Telles (2009), Benedetti (2010), Serrani (2005) entre otros.

PALABRAS-CLAVE: Teletandem; Formación de profesores; Interculturalista; Aprendizaje de lenguas.

\section{REFERÊNCIAS}

BENEDETTI, A.M.; CONSOLO, D.A.; VIEIRA-ABRAHÃO, M.H. (Orgs.). Pesquisas em ensino e aprendizagem no Teletandem Brasil: linguas estrangeiras para todos. Campinas: Pontes, 2010. 
CELANI, M. A. A. Perguntas ainda sem resposta na formação de professores de línguas. In: GIMENEZ, T; MONTEIRO, M. C. G. (Orgs). Formação de professores de Linguas na América Latina e Transformação Social. Campinas: Pontes, p. 57-67, 2010.

CORACINI, M. J. Língua materna-estrangeira: entre saber e conhecer. In: - A celebração do outro: arquivo, memória e identidade: línguas (materna e estrangeira), plurilinguismo e tradução. Campinas: Mercado de Letras, 2007, p. 149-162.

MATOS, D. C. V. S. Formação intercultural de professores de espanhol e materiais didáticos. Abehache, $\mathrm{n}^{\circ}$ 6, 2014.

MENDES, Ciro. M. Crenças sobre a lingua inglesa: o antiamericanismo e sua relação com o processo de ensino-aprendizagem de professores em formação. 2009. 189 f. Dissertação (Mestrado em Estudos Linguísticos) - Instituto de Biociências, Letras e Ciências Exatas, Universidade Estadual Paulista, São José do Rio Preto, 2009.

RODRIGUES, Denize G. A articulação língua-cultura na coconstrução da competência intercultural em uma parceria de teletandem (português/ espanhol). 2013. 188 f. Dissertação (Mestrado em Estudos Linguísticos) - Instituto de Biociências, Letras e Ciências Exatas, Universidade Estadual Paulista, São José do Rio Preto.

SALOMÃO, Ana Cristina Biondo. A cultura e o ensino de lingua estrangeira: Perspectivas para a formação continuada no projeto teletandem. 2012. 270 f. Tese (Doutorado em Estudos Linguísticos) - Instituto de Biociências, Letras e Ciências Exatas, Universidade Estadual Paulista, São José do Rio Preto.

SERRANI, S. Discurso e cultura na aula de língua: currículo, leitura, escrita. Campinas: Pontes, 2005.

SILVA, A.C.P. Multimodalidade na aprendizagem colaborativa de português e espanhol como linguas adicionais. Dissertação. (Mestrado Profissional em Formação de Professores). Universidade Estadual da Paraíba, Campina Grande, 2018.

SOUZA, F.M. Tecnologias digitais como mediadoras do processo de ensino-aprendizagem numa perspectiva sociocultural. Relatório final (Estágio de pós-doutorado em Educação Contemporânea). Centro Acadêmico do Agreste. Universidade Federal de Pernambuco: UFPE, 2016.

SOUZA, M. G. de. Teletandem e mal-entendidos na comunicação intercultural online em língua estrangeira, 2016174 f. Tese (Doutorado em Estudos Lingüísticos Instituição De Ensino) Universidade Estadual Paulista Júlio de Mesquita Filho (São José do Rio Preto), São José do Rio Preto.

TELLES, J. A. Teletandem: um contexto virtual, autônomo e colaborativo para aprendizagem de línguas estrangeiras no século XXI. Campinas: Pontes Editores, 2009. 
; MAROTI, F. A. Teletandem: Crenças e respostas dos alunos. In: PINHO, S. Z.; SAGLIET'TI, J. R. O. C. Núcleos de ensino da UNESP: artigos dos projetos realizados em 2006. São Paulo: Cultura Acadêmica, 2008.

; VASSALLO, M.L. Ensino e aprendizagem de línguas em tandem: princípios teóricos e perspectivas de pesquisa. In: TELLES, J.A. (Org). Teletandem: um contexto virtual, autônomo e colaborativo para aprendizagem de linguas estrangeiras no século XXI. Campinas: Pontes Editores, 2009, p. $19-42$.

VASSALLO, Maria Luisa. “Pequeno dicionário de Tandem”. Teletandem News. Boletim mensal do grupo de pesquisa Teletandem Brasil: Linguas estrangeiras para todos, 1,2, setembro de 2006, p. 6-7. Disponível em: < https://drive.google.com/open?id=1GZkfdyJC1qdazArrbbuwvQskmOeodE0_>Acesso em: 25 jan. 2019.

ZAKIR, Maisa de Alcântara. Cultura e (m) telecolacoração: uma análise de parcerias de teletandem institucional. 232 f. Tese (Doutorado em Estudos Linguísticos) - Instituto de Biociências, Letras e Ciências Exatas, Universidade Estadual Paulista, São José do Rio Preto.

Recebido em: 31/05/2019.

Aprovado em: 29/07/2019. 